\title{
NUMERICAL ANALYSIS OF FLOW THROUGH STILLING BASIN USING CFD MODEL
}

\section{Postaraj Khadka}

M.Sc. Student, Department of Civil Engineering, Pulchowk Campus, Institute of Engineering, Tribhuvan University, Nepal

\section{Santosh Bhattarai}

Assistant Professor, Department of Civil Engineering, Pulchowk Campus, Institute of Engineering, Tribhuvan University, Nepal

\section{Bhola Nath Sharma Ghimire}

Professor, Department of Civil Engineering, Pulchowk Campus, Institute of Engineering, Tribhuvan University, Nepal

\section{Ram Krishna Regmi}

Assistant Professor, Department of Civil Engineering, Pulchowk Campus, Institute of Engineering, Tribhuvan University, Nepal

Corresponding Author Email: postraj24@gmail.com; santoshsumi9@gmail.com

\begin{abstract}
A performance study of a stilling basin located downstream of $140 \mathrm{~m}$ high dam was attempted in the study using numerical simulation. The hydraulic characteristics of the stilling basin of 140-MW Tanahu (Upper Seti) Hydropower Project situated in Tanahu district in Nepal were investigated by numerical simulation using Computational Fluid Dynamics (CFD) modelling. The flow patterns, velocities at various locations with three different elevations: 293.00, 305.00, 309.00 masl and water levels along a main water course in stilling basin were recorded. A comparative study was made in order to evaluate the capability of the computational fluid dynamics on modeling stilling basin flow, by using results obtained from physical modeling and CFD simulation. FLOW-3D that solves Reynolds-averaged NavierStokes (RANS) equations, was used to model the numerical model setup. The flow behavior inside the stilling basin was well represented by the numerical model and there was reasonably good agreements in flow characteristics between the physical and numerical models. The deviations in water levels between physical and numerical model were below $1.9 \mathrm{~m}$ and that in flow velocities were below $30 \%$.
\end{abstract}

Keywords: Stilling Basin, Numerical Modeling, Turbulent Model, Computational Fluid Dynamics, FLOW-3D 
Cite this Article: Postaraj Khadka, Santosh Bhattarai, Bhola Nath Sharma Ghimire and Ram Krishna Regmi, Numerical Analysis of Flow through Stilling Basin using CFD Model, International Journal of Civil Engineering and Technology, 11(6), 2020, pp. 62-71.

https://iaeme.com/Home/issue/IJCIET?Volume $=11 \&$ Issue $=6$

\section{INTRODUCTION}

Spillways are basically dam appurtenances providing a safe passage of floods from the reservoir into the downstream river reach. The flow having the potential energy caused due to water level at the reservoir has high kinetic energy when passed from spillway to downstream. Energy dissipation structures or the stilling basin are used to dissipate the kinetic energy created by the flow. The magnitude of energy that should be dissipated at high dams with large spillway is enormous. The passage of water from a reservoir into the downstream river reach involves different hydraulic phenomena such as the transition into supercritical flow, supercritical non-aerated and aerated flow on the spillway, possibly flow through a freefalling jet, entry into the stilling basin with a transition from supercritical to subcritical flow, and high turbulences after the transition into the stream beyond the basin or plunge pool [1].

The complex phenomenon of stilling basin hydraulics has been studied mostly with physical hydraulic model experiments. However, the physical model tests are very expensive, fairly time consuming and there are many uncertainties and difficulties associated with the scaling effects [2]. However, the recent development of computer technology has provided a solution to complicated hydraulic problems using numerical simulations. The history of the Computational Fluid Dynamics started in the early 1970's. Digital modeling of open-channel hydraulics had begun in the 1980s with open-source, one-dimensional solutions of steadystate surface profiles published by the U.S. Army Corp of Engineers (USACE), and included a variety of 1-D, 2-D, and 3-D open-source and for-profit software solutions by the 1990s [3].

A study of a free surface three-dimensional CFD model to the tailrace of The Dalles Project was found to be in good agreement with physical models [4]. The comparative study between RNG and standard k- $\varepsilon$ turbulence models concluded that the RNG model was found to perform better near the bed regions in submerged hydraulic jumps [5] and in compound stilling basins [6]. The characteristics of the hydraulic jump in a stilling basin of multihorizontal submerged jets were studied by using VOF RNG k- $\varepsilon$ and Mixture RNG k- $\varepsilon$ turbulence models, and the numerical simulation results such as water depth, velocity profile and pressure distribution were verified by a series of model experiments [7]. The investigation of behavior of a flow inside a hydraulic jump stilling basin through the CFD modeling techniques showed that the behavior of the turbulent flow inside the stilling basin was well represented and the results: water levels, mean velocities and instantaneous pressures, in various points of the flow were in good agreements with physical model results $[8,9]$.

The analysis of numerical and experimental modeling approach to a typified United States Bureau of Reclamation Type II (USBR II) stilling basin showed that both models were able to successfully reproduce the case study in terms of hydraulic jump shape, velocity profiles, and pressure distributions [10].

This study presents an evaluation of performance of the stilling basin located downstream of $140 \mathrm{~m}$ high dam through numerical simulation. The flow through $140 \mathrm{~m}$ high dam spillway with complex topography downstream created many problems such as bank or side scouring during the design phase. The main objective of this research is to investigate the characteristics of turbulent flow in the stilling basin using a free-surface three-dimensional Computational Fluid Dynamics (CFD) numerical model aiming to validate the results between numerical and previously completed physical models. The study also evaluates the 
capacity of the stilling basin located downstream of high dam. The turbulent flow inside the stilling basin is described in terms of flow patterns, flow velocities and water levels at various locations. The commercially available CFD model software, FLOW-3D developed by Flow Science was applied. The results of this research work were deliberated to strengthen the knowledge of the fluid flow taking place in stilling basins that helps to increase their performance and to contribute to the adaptation of existing dams to higher discharges than those considered in their design.

\section{DESCRIPTION OF MODEL AND PHYSICAL TEST}

The project is located $150 \mathrm{~km}$ west of Kathmandu on Seti River near Damauli of Tanahu District of Province 4 of Nepal. This is a storage type project with an installed capacity of 140 MW. The physical model data used in this study for comparison was adopted from the final report of the "Hydraulic Model Testing of Headworks of Upper Seti Hydropower Project for Detailed Engineering Study" provided by Tanahu Hydropower Limited. The study was carried out by Hydro-Lab Pvt. Ltd. in 2012 for providing input to the detailed design of headworks and its components.

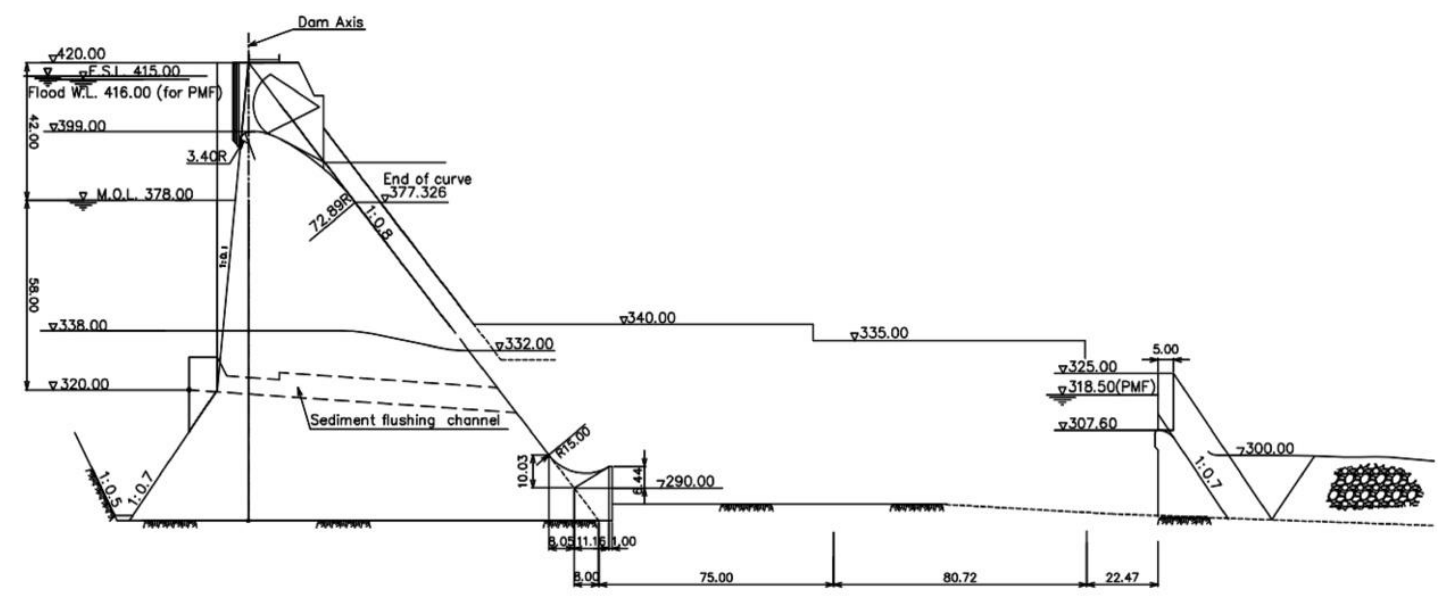

Figure 1. Longitudinal section of stilling basin with spillway (in m)

The stilling basin consists of a roller bucket type of energy dissipater with radius $15.0 \mathrm{~m}$, sill height $6.4 \mathrm{~m}$ and releasing angle of 30 degree as shown in figure 1 . The roller bucket followed by horizontal floor at 290.00 masl extends up to $105 \mathrm{~m}$ (along center line of dam) downstream. Some of the other features are: (i) Dam crest elevation: $420 \mathrm{~m}$ masl, (ii) Spillway type: Chute, (iii) Overflow crest elevation: 399 m masl, (iv) Full supply level: 415 $\mathrm{m}$, and (v) No. of opening: three.

Froude's model law was used for the physical hydraulic modelling and the undistorted scale adopted for this model was 1:60. Due to unacceptable hydraulic performance of the initial design; modifications were made to improve the performance of the stilling basin. Measurement of the water levels along the main water course and flow velocities at various points in the stilling were shown in figure 2 . The flow patterns were also observed for visual inspection. Velocities at any point were measured three times. Each measurement was the average of 60 seconds time interval. All spillway gates were opened during simulation. 


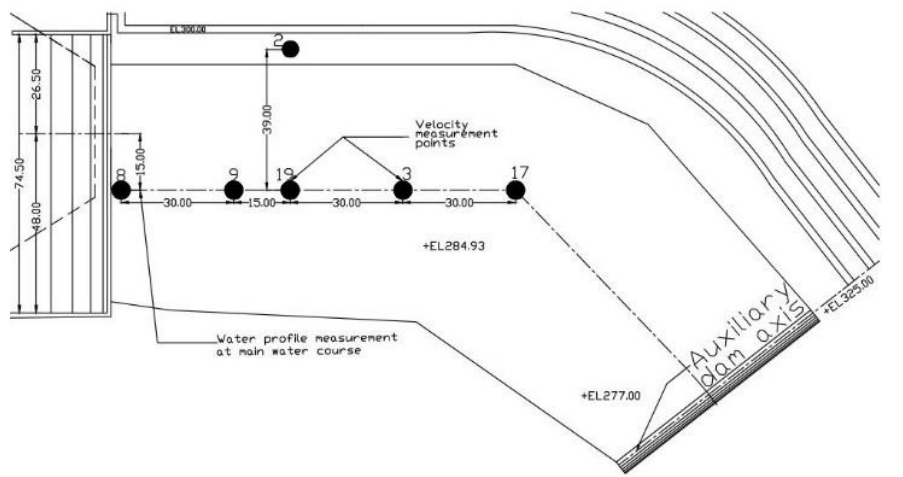

Figure 2 Plan of measurement points in the stilling basin (in m)

\section{NUMERICAL METHODOLOGY}

Computational fluid dynamics (CFD) is the application of algorithm and numerical techniques to solve fluid flow problems [11, 12]. CFD codes are structured around the numerical algorithms which can tackle the complex fluid flow problems. All codes contain three main stages: (i) a pre-processor (ii) a solver and (iii) a post-processor (results extraction and interpretation). In addition, validation is also an important aspect for stilling basin modeling. The models are set up so that the results can be compared with published data obtained by using appropriate theory or previous physical model tests. A general methodology for CFD modeling is summarized in the flowchart in figure 3 with activities of each stage.

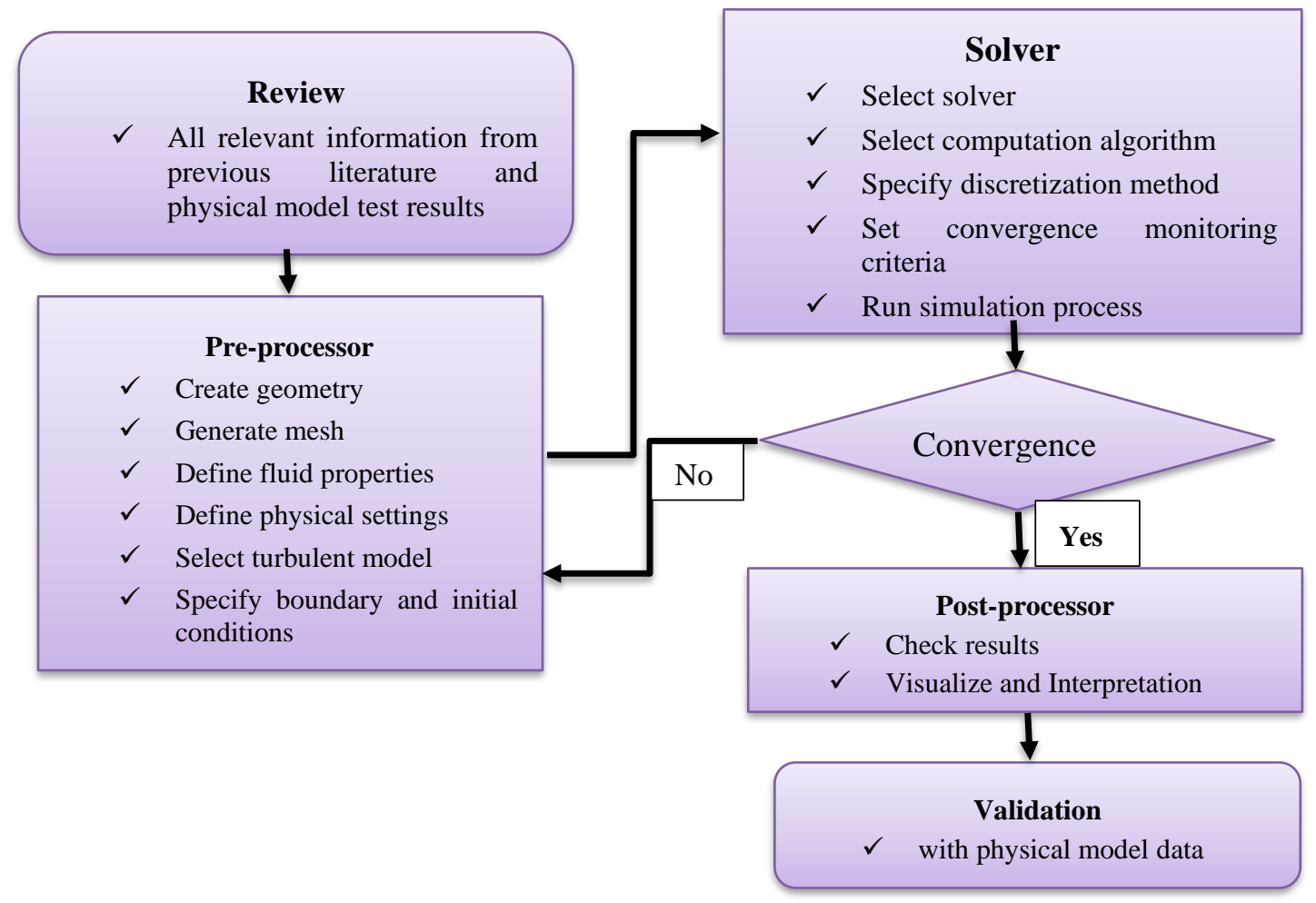

Figure 3 Flowchart of numerical methodology 


\section{NUMERICAL MODEL}

In this study, the numerical model used the commercial CFD code, FLOW-3D to analyze the turbulent flow. This is rather satisfactory software for the solutions of equations that represent the free surface turbulent flow [13]. The prototype scale dimensions were considered for the numerical model.

\subsection{Flow-3D and Governing Equations}

Flow-3D is a powerful tool for complex fluid modeling problems. Flow-3D solves the NavierStokes equations in three dimensions to simulate the fluid flow equations together with the continuity and momentum equations for the turbulence quantities. To solve the RANS equations, Flow-3D uses the finite volume method. A rectangular grid of cells is formed that subdivides the computational domain. A flow continuity equation is obtained from the law of conservation of mass and writing balance equation for a fluid element. General continuity equation is presented as:

$$
V_{f} \frac{\partial \rho}{\partial t}+\frac{\partial}{\partial x}\left(\rho u A_{x}\right)+\frac{\partial}{\partial y}\left(\rho v A_{y}\right)+\frac{\partial}{\partial z}\left(\rho w A_{z}\right)=0
$$

where $V_{f}$ indicates the fraction of open volume to flow; $\rho$ indicates fluid density; $(u, v$, $w)$ indicate velocity components in the directions of $(x, y, z) ; A_{x}, A_{y}$ and $A_{z}$ indicate the fraction of open level in $x, y$ and $z$ directions respectively.

Fluid momentum equations with velocity components of $(u, v$, and $w)$ in three different dimensions are presented as following:

$$
\begin{gathered}
\frac{\partial u}{\partial t}+\frac{1}{V_{F}}\left(u A_{x} \frac{\partial u}{\partial x}+v A_{y} \frac{\partial u}{\partial y}+w A_{z} \frac{\partial u}{\partial z}\right)=-\frac{1}{\rho} \frac{\partial p}{\partial x}+G_{x}+f_{x} \\
\frac{\partial v}{\partial t}+\frac{1}{V_{F}}\left(u A_{x} \frac{\partial v}{\partial x}+v A_{y} \frac{\partial v}{\partial y}+w A_{z} \frac{\partial v}{\partial z}\right)=-\frac{1}{\rho} \frac{\partial p}{\partial y}+G_{y}+f_{y} \\
\frac{\partial w}{\partial t}+\frac{1}{V_{F}}\left(u A_{x} \frac{\partial w}{\partial x}+v A_{y} \frac{\partial w}{\partial y}+w A_{z} \frac{\partial w}{\partial z}\right)=-\frac{1}{\rho} \frac{\partial p}{\partial z}+G_{z}+f_{z}
\end{gathered}
$$

In these equations, $\left(G_{x}, G_{y}, G_{z}\right)$ indicates mass acceleration and $\left(f_{x}, f_{y}, f_{z}\right)$ indicate viscosity accelerations.

\subsection{Free Surface Modeling}

FLOW-3D uses the volume-of-fluid (VOF) method developed mathematically by Flow Science to track the free surfaces and material interface $[14,15]$. The VOF technique is based on the idea of recording in each grid cell the fractional portion of the cell volume that is occupied by liquid. A variable named fraction of fluid $(F)$ was used to determine the fractional volume of the main fluid (i.e., water in the present case). The $F(x, y, z$ and $t)$ function represents the volume of fluid per unit volume and satisfies the equation:

$$
\frac{\partial F}{\partial t}+\frac{1}{V_{F}}\left[\frac{\partial}{\partial x}\left(F A_{x} u+F A_{y} v+F A_{z} w\right)\right]=0
$$

The value of $F$ reaches to 1 when the cell is completely filled with water and to 0 when it is empty. The location of a free surface is where $F$ changes from 0.0 to 1.0 .

\subsection{Turbulent Modeling}

The numerical modeling of the flow inside of the stilling basin is complex phenomena due to the high intensity of the turbulence and the recirculation which is associated with the 
hydraulic jump. There are two more sophisticated and more widely used turbulence models, namely: $k-\varepsilon$ and RNG $k-\varepsilon$ models that consist of two transport equations for the turbulent kinetic energy, $k$ and its dissipation, $\varepsilon$ [16]. To represent the turbulent flow characteristics, the RNG-based $k-\varepsilon$ turbulence model was used. This model is derived from the instantaneous Navier-Stokes equations that uses a mathematical technique called 'renormalization group' (RNG) $[17,18]$. The RNG $k-\varepsilon$ model has a quite similar form to the standard $k-\varepsilon$ model. The turbulence kinetic energy, $k$, and its rate of dissipation, $\varepsilon$, are obtained from the transport equations as given below:

$$
\begin{gathered}
\frac{\partial k}{\partial t}+\frac{1}{V_{F}}\left\{u A_{x} \frac{\partial k}{\partial x}+v A_{y} \frac{\partial k}{\partial y}+w A_{z} \frac{\partial k}{\partial z}\right\}=P+G+D i f f-\varepsilon \\
\frac{\partial \varepsilon}{\partial t}+\frac{1}{V_{F}}\left\{u A_{x} \frac{\partial \varepsilon}{\partial x}+v A_{y} \frac{\partial \varepsilon}{\partial y}+w A_{z} \frac{\partial \varepsilon}{\partial z}\right\}=\frac{C_{1 \varepsilon} \cdot \varepsilon}{k}\left(P+C_{3 \varepsilon} \cdot G\right)+D D i f f+C_{2 \varepsilon} \cdot \frac{\varepsilon^{2}}{k}
\end{gathered}
$$

where, $P$ is shear production, $G$ is buoyancy production, Diff and DDiff represent diffusion and $C_{1 \varepsilon}, C_{2 \varepsilon}, C_{3 \varepsilon}$ are constant. In the RNG model, $C_{1 \varepsilon}=1.42$ and $C_{2 \varepsilon}=1.68$.

The equation constants that are found empirically in the standard $k-\varepsilon$ model are derived explicitly in the RNG model. In particular, the RNG model is known to describe more accurately swirling flows, low intensity turbulence flows and flows having strong shear regions $[19,20]$.

\subsection{Model Setup}

During the simulation process for each case, the global tab was specified with one fluid, incompressible flow, and a free surface or sharp interface being selected. Also, the fluid properties were specified as those for water at 20 degree Celsius for all the simulations. Several other model parameters remained generally constant.

In the physics tab, the gravity and non-inertial reference frame option was activated with gravitational acceleration in the vertical or z-direction being set to negative $9.81 \mathrm{~m} / \mathrm{s}^{2}$ and the viscosity and turbulence option was also activated with Newtonian viscosity being applied to the flow along with the selection of renormalization group (RNG) turbulence model.

\subsubsection{Geometry and Meshing}

The entire geometry of the 3-dimensional model consisting a dam spillway and stilling basin with energy dissipater (figure 4) was drawn in AutoCAD-3D and exported in stereolithographic (stl) file format. The stl images were then directly imported to Flow-3D.

The domain of the present work was meshed using a structured rectangular hexahedral mesh

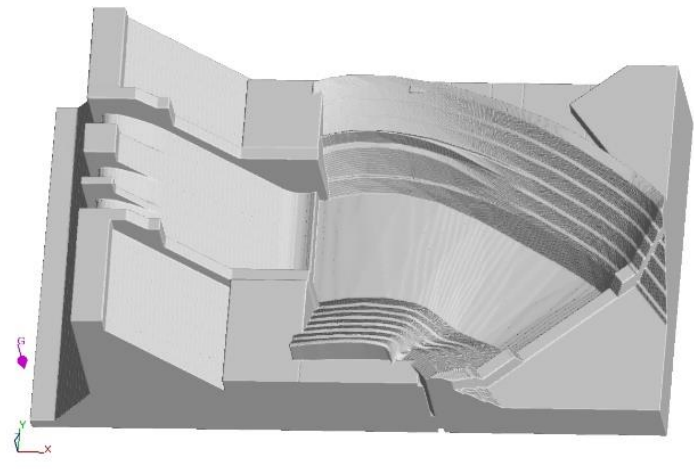

Figure 4. 3-D Model Geometry

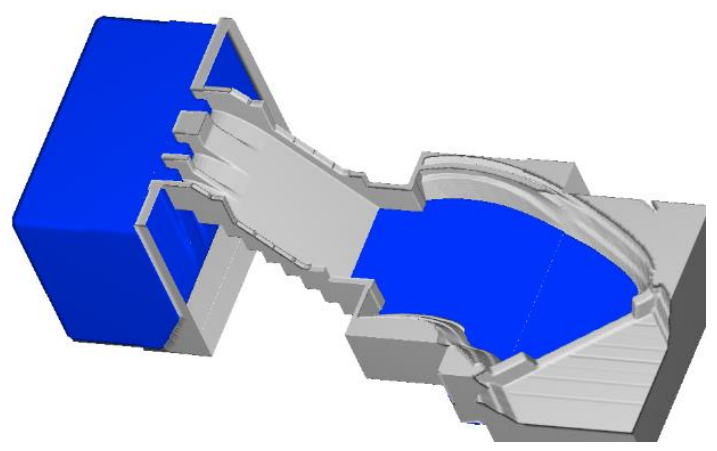

Figure 5. Flow Intialization 
with 16 different mesh blocks. The domain covered $150 \mathrm{~m}$ upstream to $340 \mathrm{~m}$ downstream from the dam axis. Starting with coarser mesh, the model was simulated by gradually refining mesh grid size. After simulating model with different cell sizes, $0.75 \mathrm{~m}$ of grid size for main study area i.e. $15 \mathrm{~m}$ upstream to $230 \mathrm{~m}$ downstream from dam axis and $1 \mathrm{~m}$ of that for remaining upstream and downstream portions were chosen for final simulation work except first mesh block i.e. $150 \mathrm{~m}$ to $15 \mathrm{~m}$ upstream of the dam axis in which the grid size was $5 \mathrm{~m}$ where the study didn't focus but used for flow development.

\subsubsection{Boundary and Initial Condition}

In the present study, the boundary condition at upstream was set to volume flow rate with unit fluid fraction and downstream to outflow condition. For the top boundary, atmospheric pressure was set whereas for the bottom and side, the wall non-slip condition was established. All the intermediate boundaries between each mesh block were set to symmetry. Exception was there for the last mesh block where the right side boundary was set to outflow because the topography was diverting towards right.

For initial condition, fluid region with corresponding elevation was defined at upstream from crest of the spillway and at downstream, hydrostatic pressure with fluid elevation was set within the stilling basin as shown in figure $\mathbf{5}$.

\section{RESULTS AND DISCUSSION}

The model was simulated during $200 \mathrm{sec}$, the time gap showed to be enough for the turbulent flow stabilization. Numerical simulations were evaluated and results of the simulations were compared with physical hydraulic model results for different return period floods. During the simulation, the flow starts from rest and is settled by the water level difference between the upstream and the downstream and it was found that at least $75 \mathrm{sec}$ was required to stabilize the flow characteristics. The measurements of the flow parameters were taken by averaging the results for 60 second time intervals after the stable flow condition.

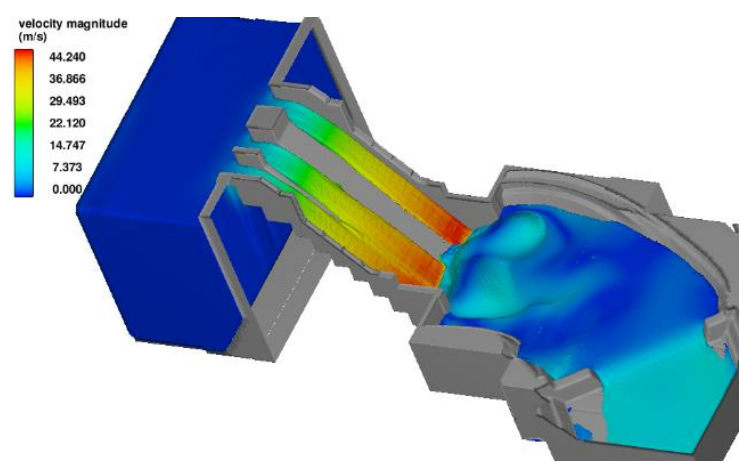

Figure 6. Velocity contour for $4,000 \mathrm{~m}^{3} / \mathrm{s}$

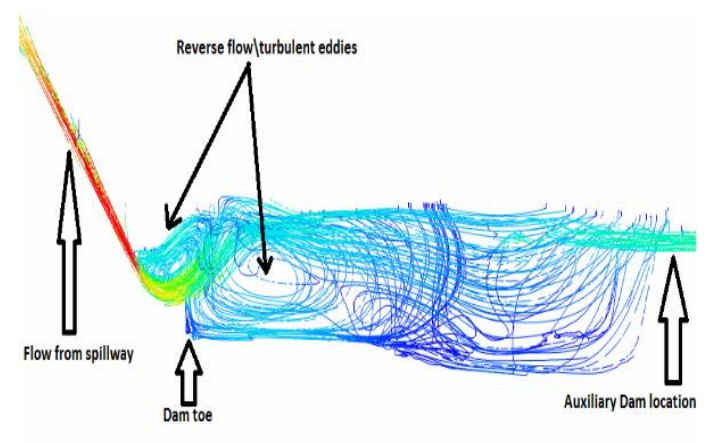

Figure 7. Flow movements at $4,000 \mathrm{~m}^{3} / \mathrm{s}$ in basin

The water profile of the spillway produced a nappe that agrees closely with the spillway profile. The figure 6 shows the velocity contours for 500 year return period flood i.e. 4,000 $\mathrm{m}^{3} / \mathrm{s}$ discharge where the flow changed from sub-critical to super-critical after the crest of the spillway as it is followed by steep sloping face. After the crest level, the flow was rapidly varying characterized by high velocity in the form of jet. This jet of flow struck the roller bucket at the toe of the dam developing vertical eddies in the bucket as shown in figure 7 . The direction of flow was towards the downstream in most of the portion of basin excluding the portion near the dam where the direction of the flow was recorded to be reversed. The height of the roller observed for discharge of $4,000 \mathrm{~m}^{3} / \mathrm{s}$ near the bucket was about $12.5 \mathrm{~m}$ which 
extended about $60 \mathrm{~m}$ downstream along the main water course that dissipated most of the excess kinetic energy of the flow before the auxiliary dam.

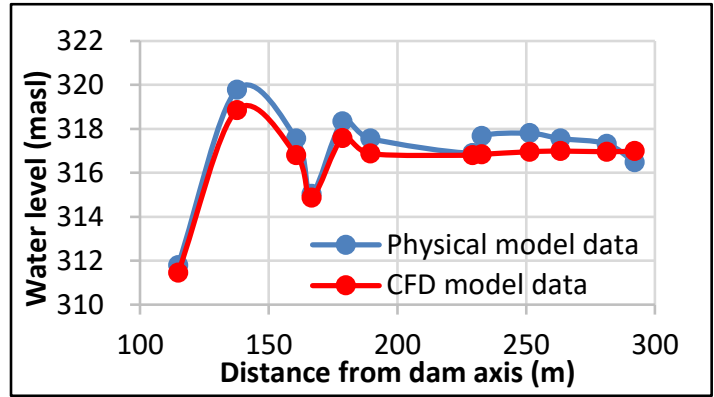

(a)

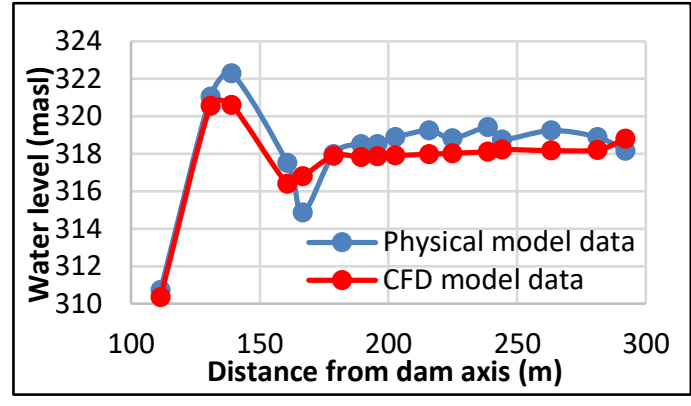

(b)

Figure 8. Water surface profile along main course in the basin at (a) 3000 , (b) $4000 \mathrm{~m}^{3} / \mathrm{s}$

The water levels at different locations along the main water course after stable flow condition in the stilling basin measured by using numerical model were used to compare with the results from physical at same locations. The water surface levels are shown in figure $\mathbf{8}$ for discharge of $3,000 \mathrm{~m}^{3} / \mathrm{s}$ (100 year return period flood) and $4,000 \mathrm{~m}^{3} / \mathrm{s}$ (500 year return period flood). The profiles for each discharge obtained from numerical model followed nearly the same profiles that were obtained from physical model along the main water course at most of the locations.

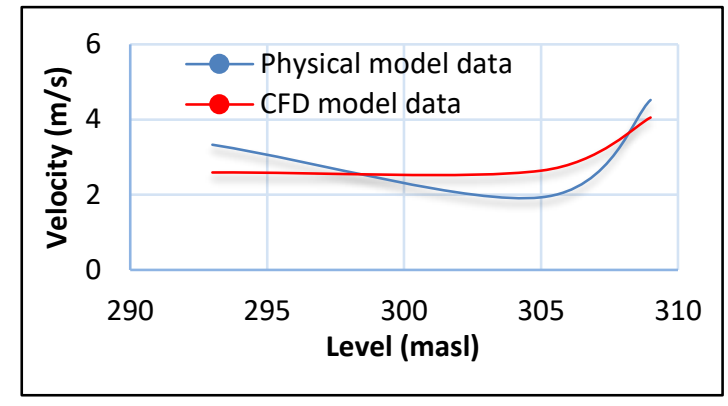

(a)

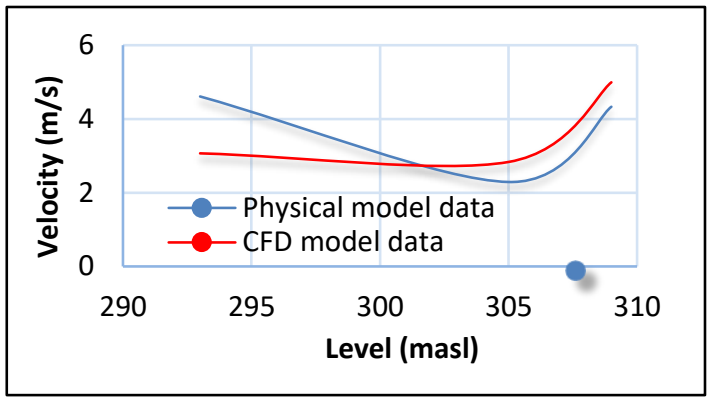

(b)

Figure 9. Average velocity at point 9 for (a) $3,000 \mathrm{~m}^{3} / \mathrm{s}$ and (b) $4,000 \mathrm{~m}^{3} / \mathrm{s}$

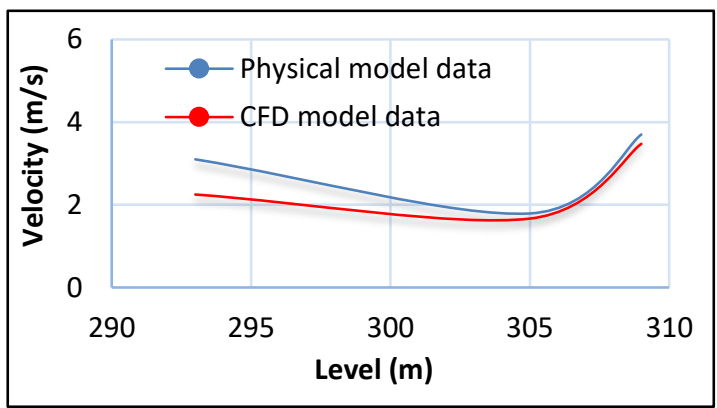

(a)

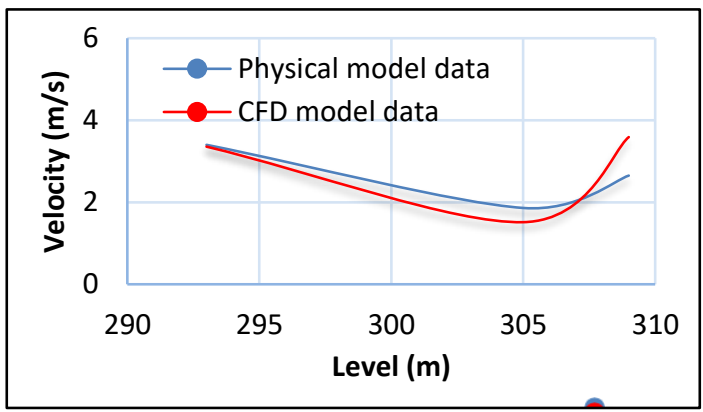

(b)

Figure 10. Average velocity at point 2 for (a) $3,000 \mathrm{~m}^{3} / \mathrm{s}$ and (b) $4,000 \mathrm{~m}^{3} / \mathrm{s}$

The velocity distributions at various points (figure 2) at three different levels: 293.00, 305.00, and 309.00 masl measured by using numerical model were used to compare the results from physical model test at same points, shown in figure from 9 to 11 . At most of the points, the average flow velocities measured by numerical model had the nearby values as obtained from the physical model. 


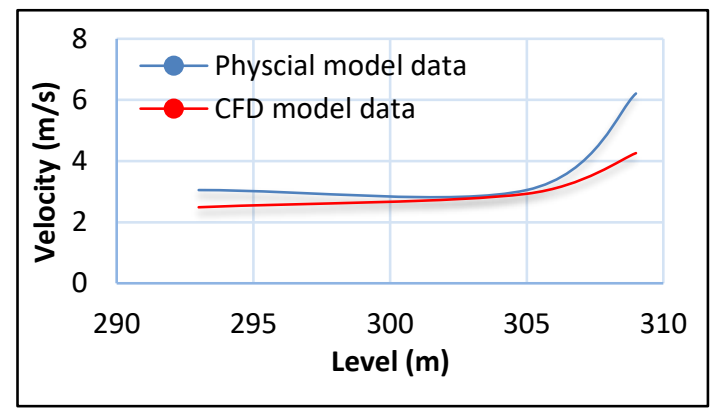

(a)

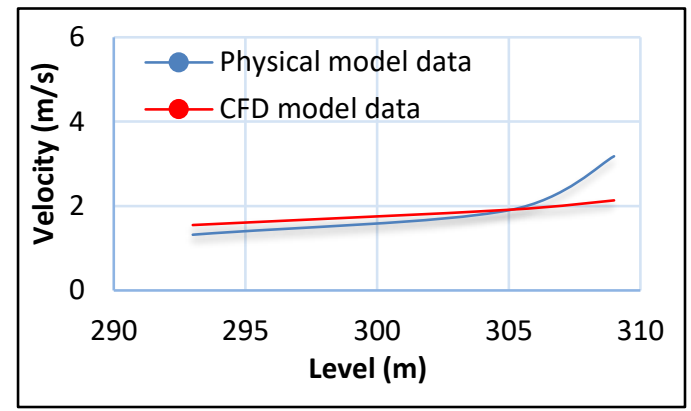

(b)

Figure 11. Average velocity for $4,000 \mathrm{~m}^{3} / \mathrm{s}$ at (a) point 19 and (b) point 3

The comparisons of results (flow patterns, velocities and water levels) between numerical and physical models were good despite slight deviations. The deviations in water levels between physical and numerical model were below $1.9 \mathrm{~m}$ and that in flow velocities were below $30 \%$. The errors were due to the scarcity of highly processing computational resource. During the sensitivity testing of mesh grid size, it was found that the comparative results didn't improve distinctly by reducing the grid size than that of the present case.

\section{CONCLUSION}

This paper attempts to verify the characteristics of turbulent flow inside the final adopted stilling basin of Tanahu Hydropower Project by using CFD modeling techniques. The numerical results so obtained were compared to the results of 1:60 scaled physical hydraulic model study conducted at Hydro-Lab Pvt. Ltd. The results from numerical modeling such as flow patterns, flow velocities and water levels inside the stilling basin at various points were compared to the results from physical models at the same locations. The behavior of the turbulent flow inside the stilling basin was well represented by the numerical model and there was reasonably good agreement between the physical and numerical models in flow characteristics. The deviations in water levels between physical and numerical models were below $1.9 \mathrm{~m}$ and that in flow velocities were below $30 \%$. Hence, this work encourages the use of a numerical modeling approach to study complex flows in hydraulic structures. Furthermore, much more computational power and a much finer grid will be needed to track the more of the important flow details inside the stilling basin.

\section{ACKNOWLEDGEMENTS}

The authors would like to thank Tanahu Hydropower Limited for providing the required data and results of a physical hydraulic model study of headworks of Tanahu hydropower project conducted at Hydro-Lab Pvt. Ltd. The authors also like to acknowledge Mr. Agraj Khakurel (IOE, TU) for providing his research license of FLOW-3D software to conduct this study.

\section{REFERENCES}

[1] Novak, P.; Moffat, A.; Nalluri, C.; Narayanan, R. Hydraulic Structures, Fourth Edition. Taylor \& Francis, 2007.

[2] Chanson, H. Hydraulics of open channel flow; Elsevier, 2004.

[3] Blazek, J. Computational fluid dynamics: principles and applications. ButterworthHeinemann, 2015.

[4] Cook, C.B.; Richmond, M.C.; Serkowski, J.A.; Ebner, L.L. Free-surface computational fluid dynamics modeling of a spillway and tailrace: Case study of the Dalles project, 2002. 
[5] Raiford, J.P.; Khan, A.A. Numerical Modeling of Internal Flow Structure in Submerged Hydraulic Jumps. World Environmental and Water Resource Congress 2006: Examining the Confluence of Environmental and Water Concerns, 2006, pp. 1-10.

[6] Zhou, Z; Wang, J. Numerical modeling of 3D flow field among a compound stilling basin. Mathematical Problems in Engineering, 2019.

[7] Chen, J.g.; Zhang, J.m.; Xu, W.1.; Wang, Y.r. Numerical simulation of the energy dissipation characteristics in stilling basin of multi-horizontal submerged jets. Journal of Hydrodynamics 2010, 22(5), pp. 732-741.

[8] Amorim, J.C.C.; Rodrigues, R.C.; Marques, M.G. A numerical and experimental study of hydraulic jump stilling basin. Advances in Hydroscience and Engineering, 4, 2004.

[9] Amorim, J.; Amante, R.; Barbosa, V. Experimental and numerical modeling of flow in a stilling basin. Proceedings of the 36th IAHR world congress 28 June-3 July, the Hague, the Netherlands, 2015.

[10] Macián-Pérez, J.F.; García-Bartual, R.; Huber, B.; Bayon, A.; Vallés-Morán, F.J. Analysis of the Flow in a Typified USBR II Stilling Basin through a Numerical and Physical Modeling Approach. Water, 12(1), 2020, pp. 227.

[11] Versteeg, H.K.; Malalasekera, W. An introduction to computational fluid dynamics: the finite volume method. Pearson education, 2007.

[12] Wilcox, D.C. Turbulence modeling for CFD, Third Edition. DCW industries La Canada, California, 2006.

[13] Flow Science, I. FLOW-3D User Manual. Santa Fe, NM, 2019.

[14] Nichols, B.; Hirt, C. Methods for calculating multidimensional, transient free surface flows past bodies. Proceedings of the 1st International Conference on Ship Hydrodynamics, 1975, pp. 253-277.

[15] Hirt, C.W.; Nichols, B.D. Volume of fluid (VOF) method for the dynamics of free boundaries. Journal of computational physics, 39(1), 1981, pp. 201-225.

[16] Harlow, F.H.; Nakayama, P.I. Turbulence transport equations. The Physics of Fluids, 10(11), 1967, pp. 2323-2332.

[17] Yakhot, V.; Orszag, S.A. Renormalization group analysis of turbulence. I. Basic theory. Journal of scientific computing, 1(1), 1986, pp. 3-51.

[18] Yakhot, V.; Smith, L.M. The renormalization group, the $\varepsilon$ - expansion and derivation of turbulence models. Journal of scientific computing, 7(1), 1992, pp. 35-61.

[19] Sabbagh-Yazdi, S.R.; Rostami, F.; Mastorakis, N.E. Turbulent modeling effects on finite volume solution of three dimensional aerated hydraulic jumps using volume of fluid. 12th WSEAS International Conference on Applied Mathematics. Cairo. Egypt, 2007, pp. 2931.

[20] Hou, Q.; Zou, Z. Comparison between standard and renormalization group k- $\varepsilon$ models in numerical simulation of swirling flow tundish. ISIJ international, 45(3), 2005, pp. 325330. 